\title{
Workshop: Hippocampal cellular activity and spatial cognitive processing
}

\author{
PHILLIP J. BEST \\ University of New Orleans, New Orleans, Louisiana
}

The following five papers discuss hippocampal cellular activity in freely behaving rats as it relates to spatial cognitive processing. They were presented at a workshop at the 1988 Meeting of the Society for Neuroscience in Toronto (Best \& Ranck 1988).

The hippocampus is an area of the brain that has received a great deal of attention recently because of its obvious involvement in higher cognitive processes. Some of the memory disturbances and disorientation seen in senile dementia of the Alzheimer's type seem to be due, in part, to damage to the hippocampus and its connections (Solomon, Pomerleau, Bennett, James, \& Morse, in press). Similar memory and information-processing disturbances are seen in other patients with damage to the hippocampus and/or its connections with the rest of the brain (Zola-Morgan, Squire, \& Amaral, 1986).

Many recent animal studies on the role of the hippocampus in cognition have focused on the role of this brain structure in the processing of spatial information. Higher animals navigate effectively about their environment by keeping track of where they are relative to important places in their environment. As they move toward or away from one particular place in the environment, they have the ability to register how that movement modifies the directions and locations of other important places. This registration of allocentric space is not a trivial problem. It requires complex cognitive processing. Lesions of the hippocampus or its major connections disrupt this ability, and, more surprisingly, certain neurons in the hippocampus - the pyramidal cells-show evidence that they are involved in the processing of this information.

The first suggestion that the hippocampus may be involved in processing information about the location of an organism in its environment came from a study by O'Keefe and Dostrovsky (1971), who reported that the activity of individual hippocampal neurons was related to the location or "place" of the animal in the environment. These cells fired selectively in one location or place in the test environment. John O'Keefe was not only the first to recognize the relationship between the cell's activity and the animal's location in space, but he and Lynn Nadel provided a theoretical framework with which to study "place-cell behavior" and the behavioral effects of lesions of the hippocampus and its connections, in their now classic book, "The Hippocampus as a Cognitive Map" (O'Keefe \& Nadel, 1978).

Although many of us found the observation and the theoretical model interesting, our original reaction ranged from healthy skepticism to sarcastic cynicism. The incorporation by O'Keefe and Nadel (1978) of the many studies of the behavioral effects of hippocampal lesions into the cognitive map theory gained credibility and acceptance prior to the belief in place-cell activity. Most notably, Abe Black joined the "spatial" camp (see Black, Nadel, \& O'Keefe, 1977), and those who were not ready to accept the cognitive map theory were at least not ignoring it. However, none of us who were recording from hippocampal neurons even bothered to attempt to replicate O'Keefe and Dostrovsky's (1971) results. Other labs were examining the relationship between hippocampal cellular activity and learning and memory (Berger, Clark, \& Thompson, 1980; Best \& Best, 1976), sleep and arousal (Mays \& Best, 1975; Olmstead, Best, \& Mays, 1973), or various behaviors (Ranck, 1973).

In 1973, Ranck reported that the activity of individual hippocampal neurons was related to very specific aspects of the animal's behavior. For example, one particular cell would fire as the animal approached a food cup and started drinking, and another might fire when the animal terminated a specific behavior. However, Ranck's extensive study revealed no tight relationship between cellular activity and the animal's location or place in the environment. One important contribution of Ranck's paper was the observation that there are two distinct classes of cellular activity in the hippocampus; the complex spike cells, which have been demonstrated to be the pyramidal cells (the main output cells of the hippocampus) and the theta cells, which are now known to be interneurons (see also Fox \& Ranck, 1975, 1981).

It was not until some of us inadvertently encountered place fields, or more accurately, were hit over the head with our own data, that we began to believe in the phenomenon and were willing to take the cognitive map theory seriously (Best \& Ranck, 1975, 1982; Olton, Branch, \& Best, 1978). Thus, in 1977 we organized a symposium at the Society for Neuroscience Meeting in Anaheim, California on "The Hippocampus as a Spatial Analyzer." The meeting was chaired by Abraham Black, and the participants were John O'Keefe, Lynn Nadel, 
James Ranck, David Olton, and myself. The main thrust of that conference was the demonstration that place-cell activity was indeed a reliable and replicable phenomenon.

Another conference was organized by Paul Solomon and John Moore at Williams College in July 1979, which included more than 30 participants investigating the hippocampus from a wide variety of theoretical and methodological perspectives. The conference was dedicated to the memory of Abe Black, who had died tragically in 1978. The conference dealt with a wide variety of theoretical interpretations of the effects of hippocampal lesions and the relationship of hippocampal cellular activity to a wide variety of behavioral constructs; however, it was clear that the effects of hippocampal lesions on spatial behavior, and the place-field activity of hippocampal neurons, were real phenomena that would have to be addressed by future attempts at comprehensive theories of hippocampal function (Moore \& Solomon, 1980).

The purpose of the current workshop is to report the progress in the examination of place-field activity. As will be obvious in the following papers, investigators are no longer merely attempting to demonstrate that place-field activity exists but, rather, they are attempting to characterize the phenomenon and to determine its limits. What information determines the extent of place fields? Can they be modified by experience? If so, how? Do these cells show characteristics that go beyond the cognitive map hypothesis? How do they interact with other regions of the brain?

The following papers discuss different aspects of placecell activity. Best and Thompson discuss the ability of the cells to respond to different environmental cues at different times and the stability of place fields over long durations. Deadwyler, Breese, and Hampson demonstrate that the location of the place fields of individual cells is not strictly dependent on the spatial features of the test apparatus, but can be changed by altering the significance or relevance of particular locations. Eichenbaum and Wiener demonstrate that the same cells can have both place properties and a nonspatial relationship to behavior. Olton, Wible, Pang, and Sakurai present the argument that the spatial correlates of hippocampal neurons do not preclude a mnemonic function for the hippocampus, or vice versa. McNaughton, Leonard, and Chen examine the relationship between the hippocampus and other areas of the brain in spatial cognitive processing.

\section{REFERENCES}

Berger, T. W., Clark, G. A., \& Thompson, R. F. (1980). Leamingdependent neuronal responses recorded from limbic system brain structures during classical conditioning. Physiological Psychology, 8, 155-167.

Best, M. R., \& Best, P. J. (1976). The effects of state of consciousness and latent inhibition on hippocampal unit activity in the rat during conditioning. Experimental Neurology, 51, 78-109.

Best, P. J., \& RANCK, J. B., JR. (1975). Reliability of the relationship between hippocampal unit activity and behavior in the rat. Society for Neuroscience Abstracts, 1, 837.

BEST, P. J., RANCK, J. B., JR. (1982). Reliability of the relationship between hippocampal unit activity and sensory-behavioral events in the rat. Experimental Neurology, 75, 652-664.

Best, P. J., RANCK, J. B., JR. (1988). Workshop on hippocampal cellular activity and spatial processing. Society for Neuroscience $A b$ stracts, 14, 595.

Black, A. H., NAdel, L., O'KeEFe, J. (1977). Hippocampal function in avoidance learning and punishment. Psychological Bulletin, 84, 1107-1129.

Fox, S. E., RANCK, J. B., JR. (1975). Localization and anatomical identification of theta and complex spike cells in the dorsal hippocampal formation of rats. Experimental Neurology, 49, 299-313.

Fox, S. E., \& RANCK, J. B., JR. (1981). Electrophysiological characteristics of hippocampal complex-spike and theta cells. Experimental Brain Research, 41, 399-410.

Mays, L. E., \& Best, P. J. (1975). Hippocampal unit activity to tonal stimuli during arousal from sleep and in awake rats. Experimental Neurology, 47, 123-129.

Moore, T., Solomon, P. R. (Eds.) (1980). The role of the hippocampus in learning and memory: A memorial workshop to A. H. Black. Physiological Psychology, 8, 145-293. (Special issue)

O'KeEFE, J., DostrovsKY, J. (1971). The hippocampus as a spatial map: Preliminary evidence from unit activity in the freely-moving rat. Brain Research, 34, 171-175.

O'KeEFE, J., \& NADEL, L. (1978). The hippocampus as a cognitive map. Oxford: Clarendon Press.

Olmstead, C. E., Best, P. J., \& MAYs, L. E. (1973). Neural activity in the dorsal hippocampus during paradoxical sleep, slow-wave sleep, and waking. Brain Research, 60, 381-391.

Olton, D. S., BRANCH, M., Best, P. J. (1978). Spatial correlates of hippocampal unit activity. Experimental Neurology, 58, 387409.

RANCK, J. B., JR. (1973). Studies on single neurons in the dorsal hippocampal formation and septum in unrestrained rats: 1 . Behavioral correlates and firing repertoires. Experimental Neurology, 41, 461555.

Solomon, P. R., Pomerleau, D., Bennett, L., James, J., \& Morse, D. L. (in press). Acquisition of the classically conditioned eyeblink response in humans over the lifespan. Psychology \& Aging.

Zola-Morgan, S., Squire, L. R., Amaral, D. G. (1986). Human amnesia and the medial temporal region: Enduring memory impairment following a bilateral lesion limited to field CAI of the hippocampus. Journal of Neuroscience, 6, 2950-2967. 